\title{
Direct communication between the right pulmonary artery and the left atrium
}

\author{
I LEKUONA, A CABRERA, R INGUANZO, C CID, J AGOSTI \\ From the Department of Cardiology and Cardiovascular Surgery, Hospital de Cruces, Bilbao, Spain
}

Direct communication between the pulmonary artery trunk or its branches and the left atrium is a rare finding and only 25 cases have been published. ${ }^{1-10}$ This anomaly has been classified into four types 27 on the basis of two main features-the presence or absence of an aneurysm in the communication and the anatomy of the pulmonary venous drainage.

We report a sixth case of the type II anomaly and discuss its embryological basis, as well as the surgical approach appropriate to each type.

\section{Case report}

A 20 year old man was referred to our hospital for evaluation of fatigue, dyspnoea, and cyanosis that had started one year before admission. On physical examination the patient was well developed and well nourished. His blood pressure was $120 / 70 \mathrm{~mm} \mathrm{Hg}$ and the pulse was regular at 75 beats $/ \mathrm{min}$. There was no chest deformity and no clubbing of the fingers. No haemangiomas of the skin or mucous membranes were present and no murmurs were found on careful auscultation.

Laboratory examination showed: haemoglobin concentration $19.9 \mathrm{~g} / \mathrm{dl}$, packed cell volume 0.60 , and red blood cell count $6.14 \times 10^{12} / 1$. The oxygen saturation of the femoral artery was reduced to $80 \%$. The arterial oxygen tension $\left(\mathrm{PaO}_{2}\right)$ while he was breathing room air was 45 $\mathrm{mm} \mathrm{Hg}(6.0 \mathrm{kPa})$.

The electrocardiogram did not show any abnormality. The chest radiograph showed a rounded posterior density on the right border of the cardiac silhouette, near the hilum. A barium swallow did not indicate anything abnormal.

A two dimensional echocardiogram showed left atrial enlargement and normal cardiac structures. An isotope scan of the lungs showed a normal appearance. On cardiac catheterisation the pressures in the right chambers were within normal limits. Angiography with injection of the contrast medium into the main pulmonary artery disclosed a direct aneurysmal communication between the right pulmonary artery and the left atrium (fig 1). The right pulmonary veins were present and draining directly into the left atrium below the aneurysmal sac (fig 2). The right to left shunt was $50 \%$.

Surgical treatment was carried out through a right thoracotomy in the fourth intercostal space. The right lung consisted of three normal lobes. Dissection of the right pulmonary hilum revealed an anomalous vessel arising from

Address for reprint requests: Dr Alberto Cabrera Duro Alda, Recalde, 35 B-2 D, 48011 Bilbao, Spain.

Accepted 8 July 1985 the posterior wall of the proximal right pulmonary artery, $\vec{\omega}$ ending in an aneurysmal structure connected with the left atrium. There were three right pulmonary veins draining directly into the left atrium below the aneurysmal formation. Both the abnormal vessel and the aneurysmal structure were ligated and the aneurysmal sac resected. Immediately the arterial oxygen concentration improved and the cyanosis disappeared. The postoperative course was uneventful and the patient was discharged 10 days after operation without $\rightarrow$ complications. Pathological examination of the specimen confirmed the arterial nature of the aneurysm.

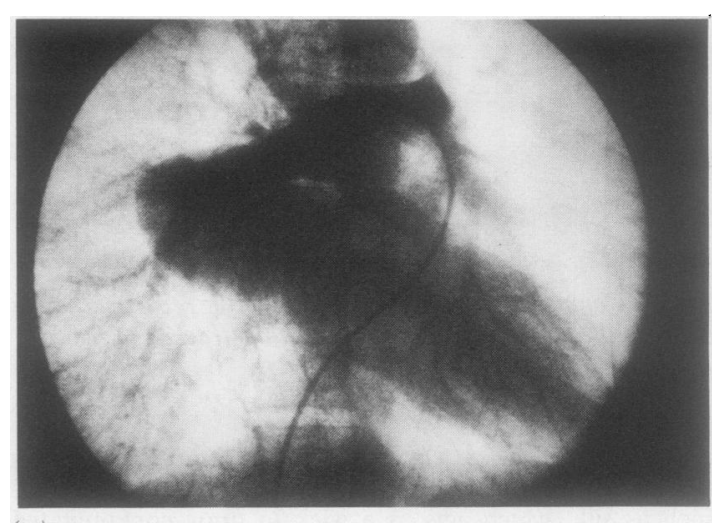

(a)

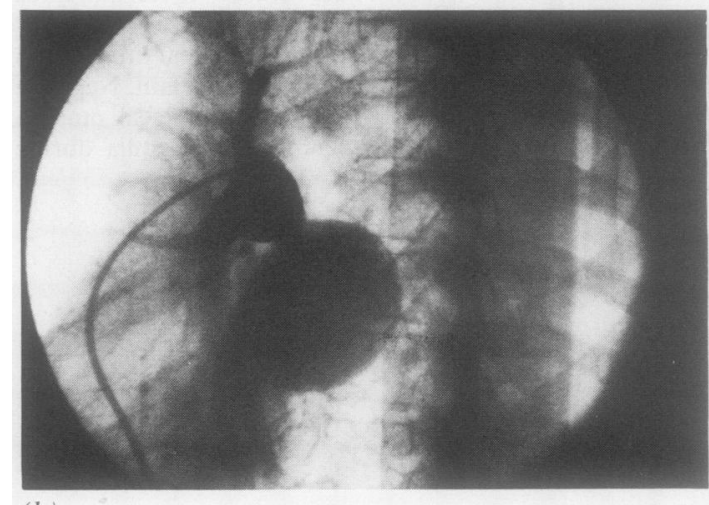

(b)

Fig 1 (a) Posteroanterior and (b) lateral views of selective $\frac{\varrho}{\Phi}$

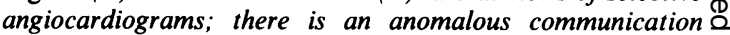
between the right pulmonary artery and the left atrium. 


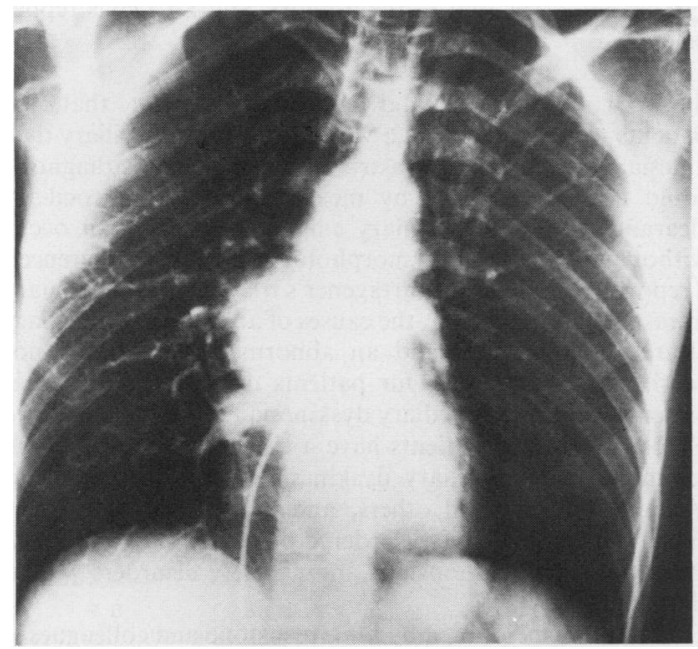

Fig 2 Posteroanterior chest radiograph: the right pulmonary veins are present and drain directly into the left atrium below the aneurysmal sac.

\section{Discussion}

Direct communication of either the pulmonary trunk or its branches with the left atrium is a rare abnormality. Reported ages ranged from 1 day to 45 years but only six patients have been below 1 year of age. Cyanosis is an outstanding feature of the entity but occasionally appears after birth.

Ohara $^{7}$ has classified the anomaly into four types: I-communication with normal veins; II-aneurysm with abnormalities of lobulation and absence of pulmonary veins; III-all veins draining into the communication; IV-aneurysm with the right veins connecting with it. The type of abnormality has been established in 19 of the reported cases: 10 were type I, five type II, one type III, and three type IV. Twenty two patients underwent surgery and eight died.

The morphogenetic mechanism is a matter for discussion and the full explanation remains to be discovered. Some have speculated about the persistence of the communication between the pulmonary artery and the pulmonary vein in the first month, when the common pulmonary vein joins the left atrium. Others ${ }^{29}$ emphasise the similarity to arteriovenous fistulas originating from agenesis of a pulmonary lobe, the dilated capillary bed giving rise to the communication. Several of the reported cases, ${ }^{3}$ with the scarcity of pathological studies, have given support to this theory. In 1984 Sassolas ${ }^{10}$ reported two cases, one of which is similar to ours. Both appear to invalidate the theory as they show coexistence of the communicating aneurysm along with normal pulmonary lobulation and normal drainage of the right pulmonary veins into the left atrium. Furthermore, the pathological examination in our case confirmed the arterial nature of the aneurysm.

Differential diagnosis in the neonatal period should include conditions associated with decreased pulmonary blood flow, chiefly pulmonary atresia, tricuspid atresia, and persistence of the fetal circulatory pattern. Anomalous connection of the systemic veins with the left atrium and pulmonary arteriovenous fistula should be borne in mind at the time of puberty if we consider the common complication of systemic embolism. Definitive diagnosis is established by selective angiography with injection into the pulmonary artery trunk.

Another controversial point is the surgical approach for correction of the defect. Simple ligation of the fistula was performed in 13 patients, nine of whom survived; ligation and division in four patients, two of whom survived; closure of the fistula by intracardiac repair in three patients, all of whom survived. We believe that types III and IV, in which veins are connected with the communication, require extracorporeal circulation, ${ }^{7}$ either to connect the veins to the left atrium or to enlarge the anastomosis. This approach avoids the risk of pulmonary oedema and late haemorrhage secondary to rupture of the aneurysm. The remaining patients can have the defect corrected by ligation and resection of the aneurysm.

\section{References}

1 Friedlich A, Bing RJ, Blount SG. Physiological studies in congenital heart disease. IX. Circulatory dynamics in the anomalies of venous return to the heart including pulmonary arterio-venous fistula. Bull Johns Hopkins Hosp 1950;86:20-57.

2 Lucas RV, Lung GW, Edwards JE. Direct communication of the pulmonary artery with the left atrium. An unusual variant of pulmonary arteriovenous fistula. Circulation 1961;24:1409-14.

3 Kroeker EJ, Adams HD, Leon AS, et al. Congenital communication between a pulmonary artery and the left atrium. Am J Med 1967;34:721-5.

4 Verel D, Grainger RG, Taylor DG. Direct communication of a pulmonary artery with the left atrium. Br Heart $J$ 1964;26:856-8.

5 Tuncalli R, Aytac A. Direct communication of pulmonary artery with the left atrium: report of a case and a proposed new entity. J Pediatr 1967;71:384-9.

6 De Souza E, Silva NA, Guliani ER, et al. Communication between right pulmonary artery and the left atrium. Am J Cardiol 1974;34:857-63.

7 O'Hara H, Ito K, Koohguchu H, et al. Direct communication between the right pulmonary artery and the left atrium. A case report and review of the literature. J Thorac Cardiovasc Surg 1979;77:742-7.

8 Cheathan JP, Barnhart DA, Gutgessell HP. Right pulmonary artery to left atrium communication. An unusual cause of cyanosis in the newborn. Pediatr Cardiol 1982;2:149-52.

9 Arendrup H. Direct communication between the pulmonary artery and the left atrium. Scand $J$ Thorac Cardiovasc Surg 1982;16:157-60.

10 Sassolas $\mathrm{F}$, Long JL, Bazio A, et al. Communication artère pulmonaire droite oreillette gauche: Une cause rare d'hypoxie refractaire chez le nouveau-né. Pediatrics 1984;3:203-8. 